\title{
Sustained release solid dispersion of MetoclopramideHCL: formulation, evaluation and pharmacokinetic studies
}

\author{
S. L. Neha, Neelam Singh, Mohd Yasir \\ Department of Pharmaceutics, I.T.S Paramedical College, Muradnagar, Ghaziabad- 201206 UP, India.
}

\begin{tabular}{|c|c|}
\hline ARTICLE INFO & ABSTRACT \\
\hline Article history: & \multirow{11}{*}{$\begin{array}{l}\text { In recent years oral controlled delivery systems have gained increased importance and interest since it is } \\
\text { necessary to improve the systemic absorption of the drugs and patient compliance. In addition, controlled } \\
\text { delivery systems maintain uniform drug levels, reduce dose and hence dose related side effect, and increase the } \\
\text { safety margin. The objective of present work was prepared sustained release solid dispersion of Metoclopramide } \\
\mathrm{HCl} \text { by solvent evaporation method. Several polymers like combination of Eudragit RSPO - Eudragit RLPO and } \\
\text { Guargum-Egg albumin as synthetic and natural polymers respectively were used. Several parameters like } \\
\text { Solubility, Partition coefficient, Drug content, Percent drug release, Bulk density, Tapped density and Carr's } \\
\text { index were evaluated and all parameters were found to be in acceptable range. The results of XRD and SEM } \\
\text { analysis were showed that the drug was converted into a solid dispersion. The In vivo studies were performed on } \\
\text { Albino Wistar rats and various pharmacokinetics parameters were determined. The whole study was showed that } \\
\text { the solid dispersion of Metoclopramide HCl sustained the release rate of drug for a prolong period of time at least } \\
12 \text { hrs and shows to increase the bioavailability and simultaneously decrease the dosing interval as well as dosing } \\
\text { amount. The formulation minimizes the blood level oscillations, dose related adverse effects and cost and } \\
\text { ultimately improve the patient compliance and drug efficiency. }\end{array}$} \\
\hline Received on: 08/10/2014 & \\
\hline Revised on: $21 / 10 / 2014$ & \\
\hline Accepted on: 08/12/2014 & \\
\hline Available online: $28 / 03 / 2015$ & \\
\hline Key words: & \\
\hline Solvent evaporation & \\
\hline technique, Bioavailability, & \\
\hline Compatibility, & \\
\hline Metacloperamide HCL etc. & \\
\hline & \\
\hline
\end{tabular}

\section{INTRODUCTION}

In recent years oral controlled delivery systems have gained increased importance and interest since it is necessary to improve the systemic absorption of the drugs and patient compliance. In addition, controlled delivery systems maintain uniform drug levels, reduce dose, side effects, and increase the safety margin. Sustained release solid dispersion formulations are the most fashionable and straightforward to formulate on a commercial scale. A wide variety of polymer matrix systems have been used in oral controlled drug delivery to obtain a desirable drug release profile, Cost effectiveness, and broad regulatory acceptance (Patel et al., 2012).Sustained release drug delivery are designed to achieve a prolonged therapeutic effect by continuously releasing medication over an extended period of time after administration of single dose of drug (Dusane et al., 2011). The USP and FDA, identify specific dissolution requirements for extended release dosage forms which involve

* Corresponding Author

Email: nehasl1990@gmail.com sampling three times, expressed as fractions of the normal dosing interval (D). Releasing of 20-50\% of the drug after 0.25 D assures that there is no dose dumping from the dosage form. The intermediate specification assures that drug release $(45-75 \%)$ over the $0.25-0.5 \mathrm{D}$ period occurs neither too slowly nor too rapidly, while the purpose of the last specification is to assure complete dissolution of the drug. From a practical stand point, sampling through $8 \mathrm{~h}$ for a twice daily product and through $12 \mathrm{~h}$ for a once daily product may be adequate, provided that not less than 75-80\% of drug has been released (Welling et al., 1988). The selection of is Metoclopramide hydrochloride is used an effective and popular drug for many type of vomiting induced by drug, disease associated(migration), radiation sickness but it less effective in motion sickness. Metoclopramide is used in long term therapy for vomiting induced by highly emetic anticancer drugs (cisplatin, etc). Metoclopramide hydrochloride inhibits gastric smooth muscle relaxation produced by dopamine, therefore increasing cholinergic response of the gastrointestinal smooth muscle. The central antidopaminergic (D2) action of Metaclopramide on CTZ is responsible for its antiemetic property. 
It accelerates intestinal transit and gastric emptying by preventing relaxation of gastric body and increasing the phasic activity of antrum. Metoclopramide also decreases reflux into the esophagus by increasing the resting pressure of the lower esophageal sphincter and improves acid clearance from the esophagus by increasing amplitude of esophageal peristaltic contractions. Studies have also shown that high doses of Metoclopramide can antagonize 5-hydroxytryptamine (5-HT) receptors in the peripheral nervous system in animals. Guar gum is a nonionic naturally occurring, hydrophilic polysaccharide obtained from the seeds of Cyamopsis tetragonolobus. It is used in solid dosage forms (binder and disintegrant), possess release retarding property and susceptibility to microbial degradation. It swells in cold water and forms viscous colloidal dispersions or sols. It is this gelling property that retards release of the drug from the dosage form. It was observed that guar gum alone acts as the release retarding polymer which follows a first-order release kinetic (Anupama et al., 2011).

The increased concentration of guar gum decreases the drug release (Deshmukh et al., 2009). Albumin have been extensively investigated in controlled release polymer as vehicles for the delivery of therapeutic agents to local sites. The exploitable features of Albumin include its reported biodegradation into natural products, its lack of toxicity and its nonantigenicity (Aydan et al., 2012).

Egg Albumin was selected as hydrophilic carriers for this study because of significant differences in their conformation and stability. Several studies on the conformational changes in ovalbumin induced by certain denaturing agents and by chemical modifications of certain amino acid have been reported (Ifat et al., 2000). In the field of modified drug delivery, interesting potentialities are offered by acrylic polymers, such as Eudragit Retard, extensively used for film coating of solid dosage forms, as well as in the preparation of inert matrices or micromatrices for controlling the drug delivery via oral or other routes. Eudragit RS (RS) and RL(RL) are copolymers of poly(ethyl-acrylate-co methyl-methacrylate-co-trimethylamino-ethyl-methacrylate chloride) [poly(EAMMA- TAMCl)]. The introduction of the hydrophilic ammonium groups (TAMCl) is aimed at modifying the permeability of the acrylic polymer. The main difference in RS and RL consists in the amount of ammonium groups: their composition is in fact EA:MMA:TAMCl=1:2:0.2 (RL) and 1:2:0.1 (RS). These polymers are insoluble in aqueous media, but are able to swell and become permeable to solutes, thanks to the presence of the ionized TAMCl groups, but in a $\mathrm{pH}$-independent manner (Eudragit Technical Sheets, Rohm, Germany) (Rosario et al., 2004).

\section{MATERIAL AND METHOD}

The Metoclopramide HCL was obtained as gift sample from Vaikunth Chemical Pvt Ltd, Gujrat (India). The synthetic polymers Eudragit RSPO and Eudragit RLPO were obtained as a gift sample from Evonic Pvt Ltd, Mumbai (India). The Natural polymers Guargum and Egg albumin was procured from Central
Drug House Pvt Ltd, N. Delhi (India). The Potassium dihydrogen phosphate, Hydrocloric acid and di sodium hydrogen phosphate were procured from Central Drug House Pvt Ltd, N. Delhi (India). All chemical and solvent were used of analytical grade.

\section{Formulation Design}

The miscellaneous factorial design with independent 2 factors and 3 levels (design expert -8 software, Statease, U.S. A) was apply to design and optimized the delivery system. Total 13 runs with formulation code B1-B13 were obtained. There was two independent factor (Polymer 1and 2) and two dependent factor (\% cumulative drug release and drug content uniformity).

Table 1: Formulation design, H-High, M-Medium, L-Lower for formulation prepared by synthetic polymers(Eudragit RSPO -Eudragit RLPO)and natural polymers (Guargum-Egg albumin).

\begin{tabular}{cccc}
\hline Run & $\begin{array}{c}\text { Formulation } \\
\text { code }\end{array}$ & Polymer1 (mg) & Polymer2 (mg) \\
\hline 1 & B1 & $1500(\mathrm{M})$ & $1500(\mathrm{M})$ \\
2 & B2 & $1000(\mathrm{~L})$ & $1000(\mathrm{~L})$ \\
3 & B3 & $1500(\mathrm{M})$ & $1500(\mathrm{M})$ \\
4 & B4 & $2000(\mathrm{H})$ & $2000(\mathrm{H})$ \\
5 & B5 & $2000(\mathrm{H})$ & $1000(\mathrm{~L})$ \\
6 & B6 & $1000(\mathrm{~L})$ & $2000(\mathrm{H})$ \\
7 & B7 & $1500(\mathrm{M})$ & $1500(\mathrm{M})$ \\
8 & B8 & $1500(\mathrm{M})$ & $1500(\mathrm{M})$ \\
9 & B9 & $1500(\mathrm{M})$ & $1500(\mathrm{M})$ \\
10 & B10 & $1500(\mathrm{M})$ & $2000(\mathrm{H})$ \\
11 & B11 & $2000(\mathrm{H})$ & $1500(\mathrm{M})$ \\
12 & B12 & $1500(\mathrm{M})$ & $1000(\mathrm{~L})$ \\
13 & B13 & $1000(\mathrm{~L})$ & $1500(\mathrm{M})$ \\
\hline
\end{tabular}

\section{Methods}

Specific quantity of Metoclopramide $\mathrm{HCl}$, Guargum, Egg albumin, Eudragit RSPO, and Eudragit RLPO were weighed. The mixture of Drug and Albumin, Guargum in different ratio were weighed and was mixed with distilled water use as a solvent. As the same way the mixture of drug, Eudragit RSPO and Eudragit RLPO were mixed with absolute alcohol with continuous stirring to achieve homogeneous mixture in magnetic stirrer at $40^{\circ} \mathrm{C}$. The solvent was evaporated at $20-40{ }^{0} \mathrm{C}$. After some time the solid residue was remained which was collected and sieved by $80 \#$ mesh and was stored in desiccators.

\section{Pre Evaluation}

\section{Drug polymer compatibility studies}

Drug polymer compatibility studies were performed by taking the combination of Drug + Guargum + Albumin (1:1:1) and Drug + Eudragit RSPO + Eudragit RLPO (1:1:1) was putted in humidity chamber for 30 days at $75 \pm 5 \%$ relative humidity and $45 \pm 2{ }^{0} \mathrm{C}$. After 30 days, these combinations were evaluated by FTIR spectrophotometer (FT/IR-4100 Jasco, Japan). Other Preformulation parameters like solubility, partition coefficient etc were determined to check the authenticity of drug.

\section{Dose determination}

The conventional dose of Metoclopramide $\mathrm{HCl}$ is $10 \mathrm{mg}$ $15 \mathrm{mg}$ four times a day but the dose is reduced to $27 \mathrm{mg}$ for 
formulating sustained release solid dispersion (Hemalatha et al., 2011; Kannan et al., 2010; Sandip et al., 2011).

$$
D_{t=} D_{i}\left(1+0.693 * t_{m} / t_{1 / 2}\right)
$$

Where, $\mathrm{D}_{\mathrm{t}}=$ total dose; $\mathrm{D}_{\mathrm{i}}=$ initial dose; $\mathrm{t}=$ time to which the drug is sustained; $t_{1 / 2}=$ half life of the drug. $\mathrm{D}_{\mathrm{t}}=10(1+0.693 \times 12 / 5) ; \mathrm{D}_{\mathrm{t}}=$ $27 \mathrm{mg}$. After the calculation the $27 \mathrm{mg}$ Metoclopramide is equivalent to $30 \mathrm{mg}$ Metoclopramide HCL twice a daily filled in capsule.

\section{Evaluation}

\section{Angle of Repose}

Angle of repose was determined using funnel method. The blend was poured through funnel that can be raised vertically until a maximum cone height (h) was obtained. Radius of the heap (r) was measured and angle of repose was calculated using the formula (Viral et al., 2011).

$$
\theta=\tan ^{-1} h / \mathbf{r}
$$

Where, $\theta$ is the angle of repose, $h$ is height of pile; $r$ is radius of the base of pile.

\section{Bulk Density}

Apparent bulk density ( $\rho$ b) was determined by pouring the blend into a graduated cylinder. The bulk volume $(\mathrm{Vb})$ and weight of powder $(\mathrm{M})$ was determined. The bulk density was calculated using the formula (Viral et al., 2011).

$$
\boldsymbol{\rho b}=\mathbf{M} / \mathbf{V}_{\mathbf{t}}
$$

\section{Tapped Density}

The measuring cylinder containing known mass of blend was tapped for a fixed time. The minimum volume (Vt ) occupied in the cylinder and weight (M) of the blend was measured. The tapped density $(\rho t)$ was calculated using the following formula (Viral et al., 2011).

$$
\rho \mathbf{t}=\mathbf{M} / \mathbf{V}_{\mathbf{t}}
$$

\section{Carr's Compressibility Index (I)}

The simplest way of measurement of free flow of powder is compressibility, an indication of the ease with which a material can be induced to flow is given by compressibility. The compressibility index of the granules was determined by Carr's compressibility index which is calculated by using the following formula (Viral et al., 2011).

$$
I=\rho t-\rho b / \rho t \times 100
$$

\section{Determination of percent yield}

The percent yield of Metoclopramide $\mathrm{HCl}$ solid dispersions can be determined by using the following expression (Tyagi et al., 2012).

Percent yield $=$ (weight of prepared solid dispersion / weight of drug + carriers) $\times 100$

\section{Drug Content}

To determine the actual amount of drug present in each milligram of the formulation. Formulation containing $100 \mathrm{mg}$ drug was taken in $100 \mathrm{ml}$ volumetric flask, dissolved in $\mathrm{pH} 6.8$ phosphate buffer and volume was made up to mark with $\mathrm{pH} 6.8$ phosphate buffer then sonicated for $15 \mathrm{~min}$. after sonication the solution was filtered. The $1 \mathrm{ml}$ sample was pipetted out from the sonicated solution into $10 \mathrm{ml}$ volumetric flask then volume was made up the $10 \mathrm{ml}$ with 6.8 phosphate buffer. Absorbance was taken at $272 \mathrm{~nm}$ by UV spectrophotometer (Shimadzu 1800, Japan).

\section{In vitro dissolution study}

The study was performed by using USP dissolution apparatus I (basket type) at $37^{\circ} \mathrm{C} \& 100 \mathrm{rpm}$ in $500 \mathrm{ml} 1.2 \mathrm{HCL}$ buffer solution for 2 hour. Then in resting time (10 hrs) the test was performed in $400 \mathrm{ml} 6.8$ phosphate buffer to make up the volume $900 \mathrm{ml}$. The $10 \mathrm{ml}$ sample was withdrawn in $30,60,90$, $120,150 \ldots .720 \mathrm{~min}$ at different interval and filtered. The absorbance of the solution was measured at $272 \mathrm{~nm}$. The concentration of metoclopramide $\mathrm{HCl}$ was calculated using slope of calibration curve and cumulative percentage release was calculated.

\section{Infrared spectral analysis}

Infrared (IR) spectra of solid dispersion prepared by natural polymers(Guargum +Egg albumin) and synthetic polymers (EudragitRSPO+EudragitRLPO) were obtained by using $\mathrm{KBr}$ disc method (1800, Shimadzu Asia Pacific Pvt. Ltd, Singapore) in the range of 4000 to $350 \mathrm{~cm}^{-1}$.

\section{X-Ray diffraction analysis}

The X-ray powder diffractograms of the API, solid dispersion, physical mixture of drug and polymers were recorded using glancing angle X-ray diffraction (GAXRD, $\mathrm{Cu} \mathrm{K} \alpha$ radiation of wavelength $1.54 \AA$, Phillips X'pert PROPW 3040, Indian Institute of Technology,Delhi) at a speed of $4 \%$ min from 10- 60 range $(2 \theta)$ at sample interval $0.02^{\circ}$ under the voltage and current of $40 \mathrm{Kv}$ and $30 \mathrm{Kv}$ respectively.

\section{Scanning electron microscopy analysis}

The sample was mounted in circular metallic sample holder available with SEMCF be arranged in a circular pattern as displayed in the SEMCF keeping under the vacuum and the sample was coated with gold partical by using BIO-RAD POLARAN sputter coater. The sample was placed in a evacuated chamber and scanned in a controlled pattern by electron beam (ZEISS EVO Series Scanning Electron Microscope EVO 50,IIT Delhi). Interaction of the electon beam with specimen produced a verity of physical phenomenon that detected are used to form images and provided the information about specimen.

\section{In Vivo study}

In vivo studies were conducting on albino wistar rats. The approval for studies was given by the animal ethical committee, ITS Paramedical (Pharmacy College), Muradnagar, Ghazaibad, UP, India. Wistar Rats were divided into three groups. The animal was fasted overnight. Drug (formulation equivalent to 
dose/body weight) was administered orally to each group as a single dose (4mg/kg of Metoclopramide HCL) through oral gauge. Blood sample were withdrawn at predetermined time interval from the orbital plexus of rat and collected in the EDTA coated vacuette tube and then centrifuged at $3000 \mathrm{rpm}$ for $10 \mathrm{~min}$ to separate the plasma. Separated plasma was mixed with $4 \mathrm{ml}$ of diethyl ether / Acetonitrile to $1 \mathrm{ml}$ plasma sample and mixed.The mixture was again centrifuged for $10 \mathrm{~min}$ at $3000 \mathrm{rpm}$. After centrifugation the upper organic layer is separated and the solvent is evaporated in a oven to dryness. The residue was added in $400 \mu \mathrm{l}$ of mobile phase and evaluated by HPLC (PU-2080Plus Jasco, Japan) (Menaka et al., 2013; Rashmika et al.,2013; Sushilkumar et al., 2011; Zheng et al., 2014).

\section{HPLC analysis}

The standard curve between area\% $\mathrm{v}_{\mathrm{s}}$ concentration(ng/ml)of metoclopramide HCL was constructed by using $\mathrm{KH}_{2} \mathrm{PO}_{4}(0.05 \mathrm{M}, \mathrm{Ph} 4.6)$ and acetonitrile in ratio of $60: 40 \mathrm{v} / \mathrm{v}$ as mobile phase. The flow rate and duration of run were $1 \mathrm{ml} / \mathrm{min}$ $10 \mathrm{~min}$ respectively. Various pharmacokinetics parameters like AUC, $\mathrm{T}_{\max } \mathrm{C}_{\max }$. etc were determined for both formulation and API and compared.

\section{Results and discussion Compatibility study}

The IR spectra of pure drug and physical mixture of drug + polymers (Metoclopramide HCL + Guargum+ Egg albumin and Metoclopramide HCL+ Eudragit RSPO+ Eudragit RLPO) was obtained to determined the compatibility of drug and polymer it was found compatible.

Results and inference of Pre Evaluation and evaluation parameters are given in table 2

Table 2: Result and observation of pre eavaluation and Evaluation.

\begin{tabular}{|c|c|c|c|}
\hline Pre Evaluation & \multicolumn{2}{|c|}{ Results } & Inference \\
\hline Solubility & \multicolumn{2}{|c|}{$74.88 \mathrm{gm}$ in $250 \mathrm{ml}$ water } & More soluble \\
\hline Partition & \multicolumn{2}{|c|}{0.403} & More \\
\hline Evaluation & $\begin{array}{c}\text { B3(Eudragit } \\
\text { RSPO+Eudragit } \\
\text { RLPO) } \\
\end{array}$ & $\begin{array}{l}\text { B7 (Guargum+ } \\
\text { Egg albumin) }\end{array}$ & \\
\hline Bulk density & $0.53-0.56 \mathrm{~g} / \mathrm{cm} 3$ & $0.54-0.57 \mathrm{~g} / \mathrm{cm}^{3}$ & \\
\hline Tapped density & $0.61-0.67 \mathrm{~g} / \mathrm{cm} 3$ & $0.60-0.68 \mathrm{~g} / \mathrm{cm}^{3}$ & \\
\hline $\begin{array}{l}\text { Compressibility } \\
\text { index }\end{array}$ & $13.1-16.4 \%$ & $10.00-16.1 \%$ & Good flow \\
\hline Angle of repose & $27.13^{\circ}-32.68^{\circ}$ & $26.5^{\circ}-30.9^{\circ}$ & Free flowing \\
\hline
\end{tabular}

\section{Percentage Yield}

The percent yield of solid dispersions prepared by synthetic polymers (Eudragit RSPO + Eudragit RLPO) and natural polymers (Guargum + Egg albumin) was found to be range between $90-95 \%$ and $80-98 \%$.

\section{Drug content uniformity}

The content uniformity of solid dispersion prepared by synthetic polymers ( Eudragit RSPO + Eudragit RLPO) and natural polymers (Guargum +Egg albumin) was found to be range between $81-97 \%$ and $80.90-94.17 \%$ respectively (table 3 ).

\section{In vitro drug release}

The in vitro drug release profile of various formulations was indicated the sustained action of formulation. The formulation is sustained for $12 \mathrm{hrs}$ than the API of drug and physical mixture of drug and polymers. The cumulative drug release of pure drug in 60 min was found to be $98 \%$ in $\mathrm{pH} 1.2 \mathrm{HCL}$ buffer and $99 \%$ in $\mathrm{pH}$ 6.8 phosphate buffer.

The cumulative drug release of physical mixture of Drug + Eudragit RSPO+Eudragit RLPO and Drug + Guargum+Albumin in 60 min was found to be $92 \%$ and $95 \%$ pH1.2 HCL buffer and $96 \%$ and $98 \%$ pH 6.8 phosphate buffer respectively. But the drug release was retarded in the formulation of solid dispersion prepared by synthetic polymers B3 ( Eudragit RSPO + Eudragit RLPO) and natural polymers B7 (Guargum + Egg albumin) in 60 min was found to be $25.3 \%$ and $23.8 \%$ respectively. The Dissolution of optimized formulation (B3 and B7) of solid dispersion was prepared by synthetic polymers (Eudragit RSPO + Eudragit RLPO) and natural polymers (Guargum +Egg albumin) in $12 \mathrm{hrs}$ was found to be $95.7 \%$ and $99 \%$ respectively(Table 3, 4).

As it is shown in tables 5 and $6 \mathrm{Y} 1$, and Y2, were fitted with a quadratic model and significant lack of fit $(\mathrm{P}<0.05)$. The positive sign of the factors represent a synergistic effect on the response, while a negative sign means an antagonist relationship. Phrases composed of two factors indicate the interaction terms and phrases with second-order factors stand for the nonlinear relationship between the response and the variable.

\section{Effect of Independent Variables on \% Cumulative drug release for formulation prepared by polymer (Eudragit RSPO and Eudragit RLPO)}

The second-order polynomial equation relating the response of (Y1) \% Cumulative drug release is given below: $\mathrm{Y}_{1}=+94.08-6.32 \mathrm{~A}-4.98 \mathrm{~B}-5.00 \mathrm{AB}-1.14 \mathrm{~A}^{2}-1.74 \mathrm{~B}^{2}$

The equation in terms of coded factors can be used to make predictions about the response for given levels of each factor. The coded equation is useful for identifying the relative impact of the factors by comparing the factor coefficients. The Model F-value of 137.76 implies the model is significant $(\mathrm{p}=<0.0001)$. "Lack of Fit F-value" of 4.55 implies the Lack of Fit is not significant $(\mathrm{P}=0.0886)$. The ANOVA test indicates that $\mathrm{A}, \mathrm{B}, \mathrm{AB} \& \mathrm{~B}^{2}$ are significant model terms. Negative coefficients of $\mathrm{A}, \mathrm{B}, \mathrm{AB}, \mathrm{A}^{2} \& \mathrm{~B}^{2}$ indicate the antagonistic effect on \%cumulative drug release(Table 5). The "Pred R Squared" of 0.9309 is in reasonable agreement with the "Adj R-Squared" of 0.9828 , indicating the adequacy of the model to predict the response of \%cumulative drug release. The 'Adeq Precision' of 41.778 indicated an adequate signal. Therefore, this model is used to navigate the design space(Table 6). As the concentration of polymers was increased the total \%cumulative drug release of the sustained release solid dispersion gets decreased. In the case of Eudragit RSPO and Eudragit RLPO as its concentration was increased it leads to decreased in \% cumulative drug release. Therefore, it was suggested to keep its concentration on the upper side to release sustained effect (Fig. 3a) 
Table 3: Observation table for cumulative drug release and Drug content uniformity of formulation B1-B13 prepared by Synthetic polymers Eudragit RSPO and Eudragit RLPO.

\begin{tabular}{|c|c|c|c|c|c|c|c|c|}
\hline \multirow[b]{2}{*}{$\begin{array}{c}\text { Formulation } \\
\text { code }\end{array}$} & \multirow{2}{*}{$\begin{array}{c}\text { Eudragit RSPO } \\
(\mathrm{mg})\end{array}$} & \multirow{2}{*}{$\begin{array}{c}\text { Eudragit RLPO } \\
(\mathrm{mg})\end{array}$} & \multicolumn{3}{|c|}{ Cumulative Drug release $(\%)$} & \multicolumn{3}{|c|}{ Drug content uniformity (\%) } \\
\hline & & & Actual value & Predicd value & $\begin{array}{c}\text { Residul } \\
\text { value }\end{array}$ & $\begin{array}{l}\text { Actal } \\
\text { value }\end{array}$ & $\begin{array}{c}\text { Predicd } \\
\text { value }\end{array}$ & Residl value \\
\hline B1 & 1000.00 & 1000.00 & 98.00 & 97.50 & 0.50 & 83.87 & 83.64 & 0.23 \\
\hline B2 & 1500.00 & 1000.00 & 96.00 & 97.33 & -1.33 & 83.00 & 83.16 & -0.16 \\
\hline B3 & 2000.00 & 1000.00 & 95.70 & 94.87 & 0.83 & 97.20 & 97.28 & -0.077 \\
\hline B4 & 1000.00 & 1500.00 & 99.00 & 99.26 & -0.26 & 84.00 & 84.23 & -0.23 \\
\hline B5 & 1500.00 & 1500.00 & 94.80 & 94.08 & 0.72 & 80.20 & 80.32 & -0.12 \\
\hline B6 & 2000.00 & 1500.00 & 85.70 & 86.63 & -0.93 & 91.40 & 91.01 & 0.39 \\
\hline B7 & 1000.00 & 2000.00 & 97.30 & 97.54 & -0.24 & 89.02 & 89.02 & 00.00 \\
\hline B8 & 1500.00 & 2000.00 & 87.50 & 87.36 & 0.14 & 82.00 & 81.68 & 0.32 \\
\hline B9 & 2000.00 & 2000.00 & 75.00 & 74.90 & 0.097 & 88.62 & 88.94 & -0.32 \\
\hline B10 & 1500.00 & 1500.00 & 94.00 & 94.08 & -0.083 & 81.00 & 80.32 & 0.68 \\
\hline B11 & 1500.00 & 1500.00 & 93.80 & 94.08 & -0.28 & 80.00 & 80.32 & -0.32 \\
\hline B12 & 1500.00 & 1500.00 & 94.00 & 94.08 & -0.083 & 80.20 & 80.32 & -0.12 \\
\hline B13 & 1500.00 & 1500.00 & 95.00 & 94.08 & 0.92 & 80.05 & 80.32 & -0.27 \\
\hline
\end{tabular}

Table 4: Observation table for cumulative drug release and Drug content uniformity of formulation B1-B13 prepared by Natural polymers Guargum + Egg albumin

\begin{tabular}{|c|c|c|c|c|c|c|c|c|}
\hline \multirow{2}{*}{$\begin{array}{l}\text { Formulation } \\
\text { Code }\end{array}$} & \multirow{2}{*}{ Guargum(g) } & \multirow{2}{*}{ Albumin(g) } & \multicolumn{3}{|c|}{ Cumulative Drug release (\%) } & \multicolumn{3}{|c|}{$\begin{array}{c}\text { Drug content uniformity } \\
(\%)\end{array}$} \\
\hline & & & $\begin{array}{l}\text { Actal } \\
\text { value }\end{array}$ & Predicd value & $\begin{array}{c}\text { Residul } \\
\text { value }\end{array}$ & $\begin{array}{l}\text { Actal } \\
\text { value }\end{array}$ & $\begin{array}{l}\text { Predicd } \\
\text { value }\end{array}$ & Residl value \\
\hline B1 & 1000.00 & 1000.00 & 99.00 & 98.59 & 0.41 & 91.20 & 91.01 & 0.19 \\
\hline B2 & 1500.00 & 1000.00 & 98.80 & 99.33 & -0.53 & 93.00 & 94.10 & -1.10 \\
\hline B3 & 2000.00 & 1000.00 & 90 & 89.88 & 0.12 & 93.20 & 92.29 & 0.91 \\
\hline B4 & 1000.00 & 1500.00 & 96.90 & 96.56 & 0.34 & 93.60 & 93.49 & 0.11 \\
\hline B5 & 1500.00 & 1500.00 & 94.50 & 95.17 & -0.67 & 93.00 & 92.76 & 0.24 \\
\hline B6 & 2000.00 & 1500.00 & 84.50 & 83.59 & 0.91 & 85.80 & 87.13 & -1.33 \\
\hline B7 & 1000.00 & 2000.00 & 98.00 & 98.74 & -0.74 & 94.17 & 94.47 & -0.30 \\
\hline B8 & 1500.00 & 2000.00 & 97.00 & 95.23 & 1.77 & 89.80 & 89.92 & -0.12 \\
\hline B9 & 2000.00 & 2000.00 & 80.5 & 81.53 & -1.03 & 80.90 & 80.48 & 0.42 \\
\hline B10 & 1500.00 & 1500.00 & 95.20 & 95.17 & 0.031 & 93.50 & 92.76 & 0.74 \\
\hline B11 & 1500.00 & 1500.00 & 95.80 & 95.17 & -0.63 & 92.00 & 92.76 & -0.76 \\
\hline B12 & 1500.00 & 1500.00 & 94.50 & 95.17 & -0.67 & 93.00 & 92.76 & 0.24 \\
\hline B13 & 1500.00 & 1500.00 & 94.60 & 95.17 & -0.57 & 93.50 & 92.76 & 0.74 \\
\hline
\end{tabular}

Table 5: Regression analysis for \% Cumulative drug release and Drug content uniformity drug release for formulation B1-B13 prepared by polymers (Eudragit RSPO and Eudragit RLPO).

\begin{tabular}{ccccc}
\hline Factor & \% Cumulative Drug Release & Drug content uniformity & \\
\hline & C E & P-Value & CE & \\
\hline Intercept & 94.08 & & 80.32 & \\
A & -6.32 & $<0.0001$ & 3.39 & $<0.0001$ \\
B & -4.98 & $<0.0001$ & -0.74 & 0.0030 \\
AB & -5.00 & $<0.0001$ & -3.43 & $<.30$ \\
$\mathrm{~A}^{2}$ & -1.14 & 0.0631 & 2.10 & $<0.0001$ \\
$\mathrm{~B}^{2}$ & -1.74 & 0.0119 & & $<0.0001$ \\
\hline
\end{tabular}

Table 6: Design summary for formulation B1-B13 prepared by polymers (Eudragit RSPO and Eudragit RLPO).

\begin{tabular}{|c|c|c|c|c|c|}
\hline \multicolumn{6}{|c|}{ Model summary for response Y1 (\% Cumulative drug release) } \\
\hline Source & Sequential p Value & Lack of fit $p$ Value & Adjusted $\mathbf{R}^{2}$ & Predicted $\mathbf{R}^{2}$ & Model Suggested \\
\hline Linear & 0.0008 & 0.0005 & 0.7096 & 0.3568 & \\
\hline $2 \mathrm{~F} 1$ & 0.0002 & 0.0099 & 0.9375 & 0.8395 & \\
\hline Quadratic & 0.0046 & 0.0886 & 0.9828 & 0.9309 & Suggested \\
\hline \multicolumn{6}{|c|}{ Model summary for response Y2 (Drug content uniformity) } \\
\hline Source & Sequential p Value & Lack of fit $p$ Value & Adjusted R & Predicted $\mathbf{R}^{2}$ & Model Suggested \\
\hline Linear & 0.3087 & $<0.0001$ & 0.0514 & -0.7061 & \\
\hline $2 \mathrm{~F} 1$ & 0.2031 & $<0.0001$ & 0.1285 & -2.0087 & \\
\hline Quadratic & $<0.0001$ & 0.4772 & 0.9942 & 0.9828 & Suggested \\
\hline
\end{tabular}

Table 7: Regression analysis for Drug content uniformity and \% Cumulative drug release drug release for formulation B1-B13 prepared by natural polymers (Guargum + Egg albumin).

\begin{tabular}{ccccc}
\hline Factor & \multicolumn{2}{c}{ \% Cumulative } & Drug Release & \multicolumn{2}{c}{ Drug content uniformity } \\
\hline & C E & P-Value & C E & P-Value \\
\hline Intercept & 95.17 & & 92.76 & $<0.0001$ \\
A & -6.48 & -0.0001 & -3.18 & 0.0009 \\
B & -2.05 & 0.0020 & -2.09 & $<0.0001$ \\
AB & -2.12 & 0.0050 & -3.82 & 0.0031 \\
$A^{2}$ & -5.09 & $<0.0001$ & -2.45 & 0.2196 \\
B $^{2}$ & 2.11 & 0.0126 & -0.75 & \\
\hline
\end{tabular}



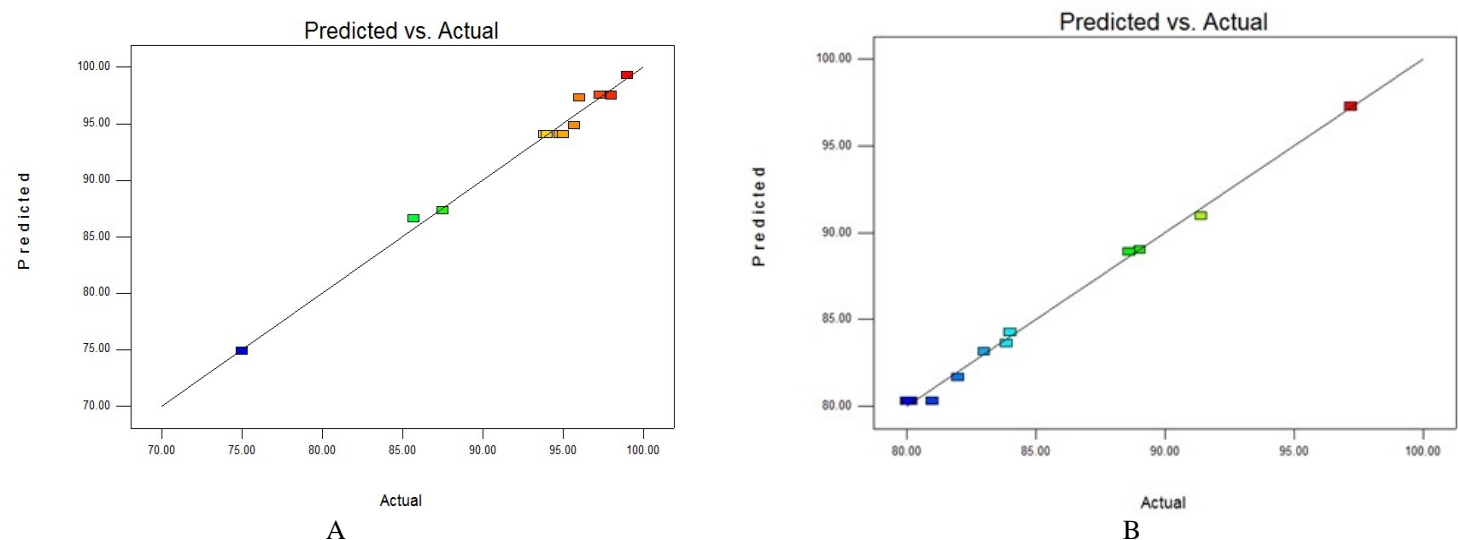

Fig. 1: Graph of actual value vs. predicted value of formulation B1-B13 prepared by synthetic polymers (Eudragit RSPO and Eudragit RLPO) for (a) \% Cumulative drug release of formulation (b) Drug content uniformity of formulation.
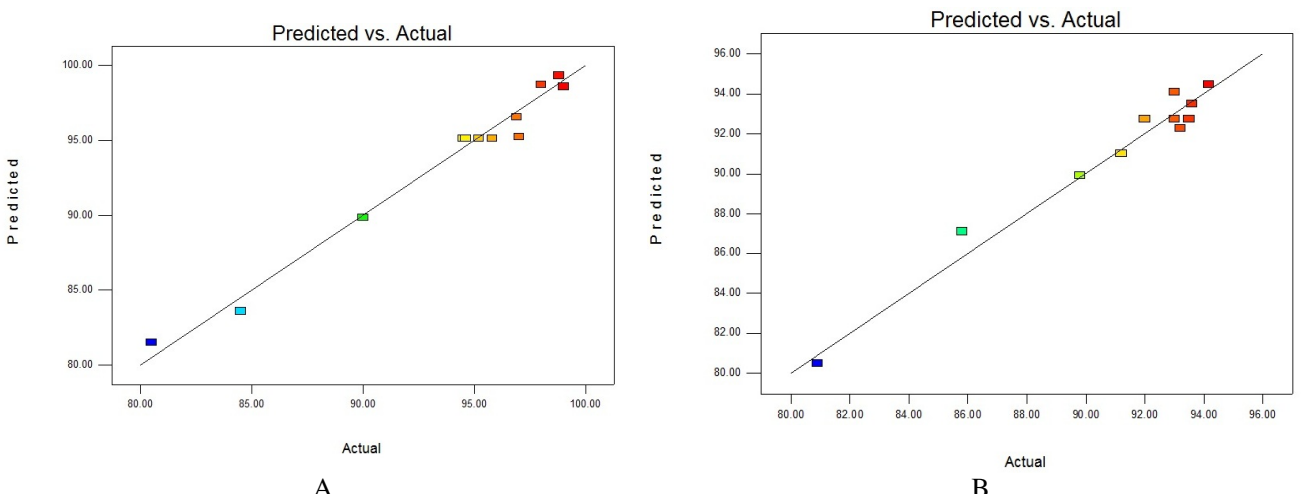

Fig. 2: Graph of actual value vs. predicted value of formulation B1-B13 prepared by natural polymers (Guargum + Egg albumin) for (a) \% Cumulative drug release of formulation (b) Drug content uniformity of formulation.

Effect of independent variables on Drug content uniformity for formulation prepared by polymer (Eudragit RSPO and Eudragit RLPO)

The second-order polynomial equation relating the response of \% drug release (Y2) is given below:

$\mathrm{Y}_{2}=+83.32+3.39 \mathrm{~A}-0.74 \mathrm{~B}-3.43 \mathrm{AB}+7.30 \mathrm{~A}^{2}+2.10 \mathrm{~B}^{2}$

The Model F-value of 413.87 implies the model is significant $(\mathrm{p}=<0.0001)$. The "Lack of Fit F-value" of 1.01 implies the Lack of Fit is not significant $(\mathrm{P}=0.4772)$. The ANOVA test indicate that $\mathrm{A}, \mathrm{B}, \mathrm{AB}, \mathrm{A}^{2}, \mathrm{~B}^{2}$ are significant model terms. Positive coefficients of $A, A^{2} \& B^{2}$ indicate the synergistic effect on drug content uniformity. Negative coefficients of $B, \& A B$ indicate the antagonistic effect on drug content uniformity (Table 5).

The "Pred R-Squared" of 0.9828 is in reasonable agreement with the "Adj R-Squared" of 0.9942. indicating the adequacy of the model to predict the response of drug content uniformity. The 'Adeq Precision' 61.277 of indicated an adequate signal. Therefore, this model is used to navigate the design space (Table 6).

As it is shown in tables 7and 8, Y1, and Y2, were fitted with a quadratic model and insignificant lack of fit $(\mathrm{P}>0.05)$. The positive sign of the factors represent a synergistic effect on the response, while a negative sign means an antagonist relationship. Phrases composed of two factors indicate the interaction terms and phrases with second-order factors stand for the nonlinear relationship between the response and the variable.

\section{Effect of Independent Variables on \% Cumulative drug release for formulation prepared by natural polymers (Guargum + Egg albumin)}

The second-order polynomial equation relating the response of $(Y I) \%$ Cumulative drug release is given below: $\mathrm{Y}_{1}=+95.17-6.48 \mathrm{~A}-2.05 \mathrm{~B}-2.12 \mathrm{AB}-5.09 \mathrm{~A}^{2}+2.11 \mathrm{~B}^{2}$

The equation in terms of coded factors can be used to make predictions about the response for given levels of each factor. The coded equation is useful for identifying the relative impact of the factors by comparing the factor coefficients.

The Model F-value of 66.21 implies the model is significant $(\mathrm{p}=<0.0001)$. "Lack of Fit F-value" of 6.58 implies the Lack of Fit is not significant $(\mathrm{P}=0.0501)$. The ANOVA test indicates that $\mathrm{A}, \mathrm{B}, \mathrm{AB}, \mathrm{A}^{2}, \mathrm{~B}^{2}$ are significant model terms. Positive coefficients of $\mathrm{B}^{2}$ in equation (1) indicate the synergistic effect on $\%$ cumulative drug release while negative coefficients of $\mathrm{A}, B, \mathrm{AB} \& \mathrm{~A}^{2}$ indicate the antagonistic effect on \%cumulative drug release (Table. 7).

The "Pred R Squared" of 0.8398 is in reasonable agreement with the "Adj R-Squared" of 0.9645 , indicating the adequacy of the model to predict the response of \%cumulative drug release. The 'Adeq Precision' of 24.879 indicated an 
adequate signal. Therefore, this model is used to navigate the design space (Table. 8). As the concentration of polymers was increased the total \%cumulative drug release of the sustained release solid dispersion gets decreased. In the case of Guargum and Albumin as its concentration was increased it leads to decreased in \%cumulative drug release. Therefore, it was suggested to keep its concentration on the upper side to release sustained effect (Fig 4.a).

Effect of independent variables on Drug content uniformity for formulation prepared by natural polymers (Guargum + Egg albumin)

The second-order polynomial equation relating the response of \% drug release (Y2) is given below:

$Y_{2}=+92.76-3.18 A-2.09 B-3.82 A B-2.45 A^{2}-0.75 B^{2}$

The Model F-value of 40.29 implies the model is significant $(\mathrm{p}=<0.0001)$. The "Lack of Fit F-value" of 3.94 implies the Lack of Fit is not significant $(\mathrm{P}=0.1092)$. The ANOVA test indicates that $\mathrm{A}, \mathrm{B}, \mathrm{AB} \& \mathrm{~A}^{2}$ are significant model terms. Negative coefficients of $A, \quad B, A^{2}, B^{2} \& \quad A B$ indicate the antagonistic effect on drug content uniformity(Table 7).

The "Pred R Squared" of 0.7732 is in reasonable agreement with the "Adj R-Squared"0.9424, indicating the adequacy signal of the model to predict the response of drug content uniformity. The 'Adeq Precision' 22.372 of indicated an adequate signal. Therefore, this model is used to navigate the design space(Table 8).

\section{Infrared spectral analysis}

IR spectroscopy was performed on pure drug Metoclopramide HCL and its solid dispersion. Pure MCP spectra showed sharp characteristic peaks at 2977.55(C-H stretching in $\mathrm{CH}_{3}$ group), 3216.68(N-H stretching in $\mathrm{NH} 2$ group),
1731.76( $\mathrm{C}=$ Ostretching in $\mathrm{C}=\mathrm{O}$ group $), 624.8(\mathrm{C}-\mathrm{Cl}$ alkyl halides group) and1508.06(C-C stretching in aromatic ring) $\mathrm{cm}^{-1}$. All the above characteristic peaks appear in the spectra of Metoclopramide $\mathrm{HCl}$ solid dispersion prepared by natural polymer Guargum+Eggalbumin and synthetic polymers (Eudragit RSPO+ Eudragit RLPO) at same wave number indicating no modification or interaction between the drug and polymers (Fig 5).

\section{$\mathrm{X}$ ray diffraction analysis}

The retardation of peaks height or no peak observation in XRD of optimized formulation prepared by synthetic polymers B3 (Eudragit RSPO-Eudragit RLPO) natural polymers B7 (GuargumAlbumin) was found that the crystalline pure drug was completely changed into amorphous solid dispersion (Fig 6).

\section{Scanning electron microscopy analysis}

The SEM analysis was also used to determine the surface structure of solid dispersion. The structure of optimized formulation prepared by synthetic polymers B3 (Eudragit RSPO-Eudragit RLPO) natural polymers B7 (Guargum-Albumin) was found to be amotphous after comparison with drug structure (Fig 7).

\section{In vivo study}

The pharmacokinetic graph between between concentration $(\mu \mathrm{g} / \mathrm{ml}) v_{\mathrm{s}}$ time(hrs) was shown that increased sustained effect of Formulation prepared by synthetic polymers B3 (Eudragit RSPO+ Eudragit RLPO) and optimized formulation prepared by natural polymers B7 (Guargum+ Egg albumin) over the effect of pure drug over the effect of pure drug (Fig 8). The in vivo study of solid dispersion of Metoclopramide $\mathrm{HCl}$ was done for determination of pharmacokinetic parameters of solid dispersion of Metoclopramide $\mathrm{HCl}$ and was compared with pharmacokinetic parameter of pure drug Metoclopramide $\mathrm{HCl}$ (Table 10).

Table 8: Design summary for formulation B1-B13 prepared by natural polymers (Guargum + Egg albumin).

\begin{tabular}{|c|c|c|c|c|c|}
\hline \multicolumn{6}{|c|}{ Model summary for response Y1 (\% Cumulative drug release) } \\
\hline Source & Sequential p Value & Lack of fit $p$ Value & Adjusted $\mathbf{R}^{2}$ & Predicted $\mathbf{R}^{2}$ & Model Suggested \\
\hline Linear & 0.0012 & 0.0011 & 0.6879 & 0.4544 & \\
\hline $2 \mathrm{~F} 1$ & 0.1864 & 0.0012 & 0.7175 & 0.3443 & \\
\hline Quadratic & 0.0003 & 0.0501 & 0.9645 & 0.8398 & Suggested \\
\hline \multicolumn{6}{|c|}{ Model summary for response Y2 (Drug content uniformity) } \\
\hline Source & Sequential p Value & Lack of fit p Value & Adjusted $\mathbf{R}^{2}$ & Predicted $\mathbf{R}^{2}$ & Model Suggested \\
\hline Linear & 0.0341 & 0.0016 & 0.3895 & -0.2644 & \\
\hline $2 \mathrm{~F} 1$ & 0.0028 & 0.0094 & 0.7617 & 0.3972 & \\
\hline Quadratic & 0.0029 & 0.1092 & 0.9424 & 0.7732 & Suggested \\
\hline
\end{tabular}

Table 9: Table of concentration $(\mu \mathrm{g} / \mathrm{ml})$ of drug and optimized formulation prepared by synthetic polymers B3(Eudragit RSPO+ Eudragit RLPO) and natural polymers B7 (Guargum+ Egg albumin) calculated by standard curve using HPLC.

\begin{tabular}{cccc}
\hline Time $(\mathbf{h r s})$ & \multicolumn{3}{c}{ Concentration in $\boldsymbol{\mu g} / \mathbf{m l}$} \\
\hline & Drug & Formulation prepared by Eudragit RSPO+ Eudragit RLPO & Formulation prepared by Guargum+ Egg albumin \\
\hline 1 & 5.813437 & 2.55866 & 2.44342 \\
2 & 10.95343 & 4.85943 & 5.4563 \\
3 & 8.7366 & 8.99682 & 8.46824 \\
4 & 7.2944 & 12.00791 & 14.75855 \\
5 & 6.05861 & 16.3991 & 12.85675 \\
6 & 5.34405 & 13.31046 & 11.15903 \\
8 & 4.404676 & 11.10713 & 10.23006 \\
10 & 3.20369 & 9.26147 & 9.57003 \\
12 & 2.00619 & 8.44577 & 9.07581 \\
\hline
\end{tabular}


Table 10: Value of pharmacokinetic parameter of drug and Solid dispersion of optimized formulation prepared by synthetic polymers B3(Eudragit RSPO+ Eudragit RLPO) and natural polymers B7 ( Guargum+ Egg albumin).

\begin{tabular}{ccccccc}
\hline Sample & Cmax & Tmax & Eli(K $\left.\mathbf{K}_{\mathbf{E}}\right)$ & AUC0_t & AUC0_inf \\
\hline API & 10.95343 & 2 & 0.125552 & 317.2134 & 333.1923 & 5.520799 \\
F-SP A3 & 16.3991 & 5 & 0.069022 & 752.1027 & 235.0541 & 10.04236 \\
F- NP A7 & 14.75855 & 4 & 0.070088 & 725.2795 & 237.6681 & 9.889695 \\
\hline
\end{tabular}

API: Drug, F-SP A3: Formulation prepared by synthetic polymers, F-NP A7: formulation prepared by natural polymers.

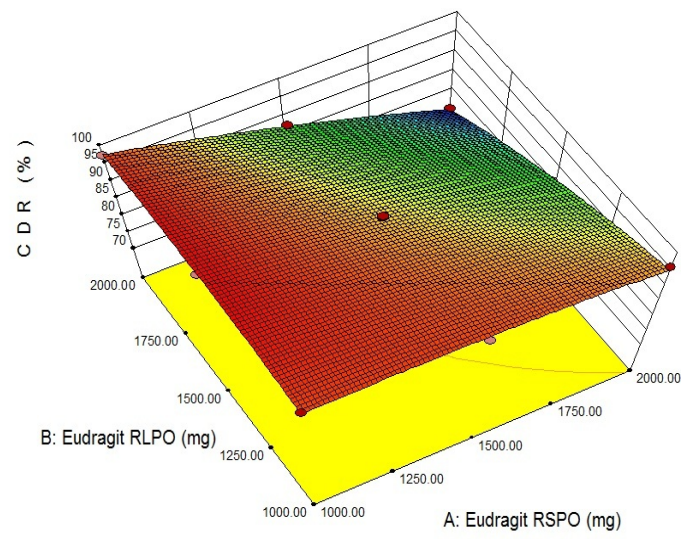

(a)

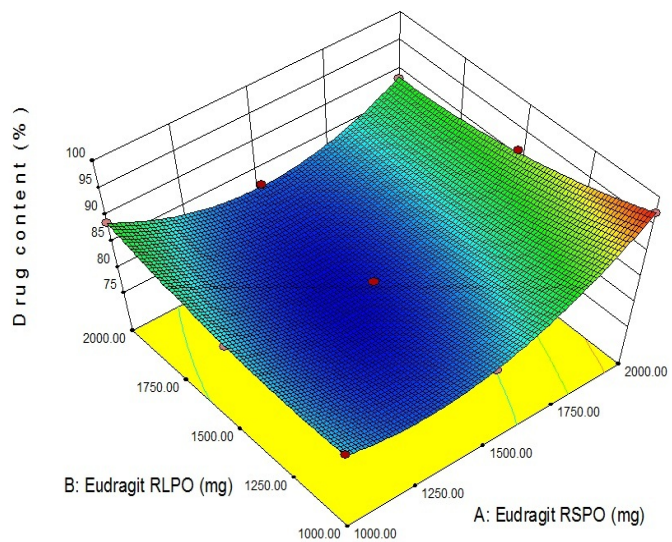

(b)

Fig. 3: 3-D surface response plots showing relative effects of Eudragit RSPO and Eudragit RLPO on (a) \% cumulative drug release (b) drug content uniformity for formulation B1-B13 prepared by Eudragit RSPO and Eudragit RLPO.

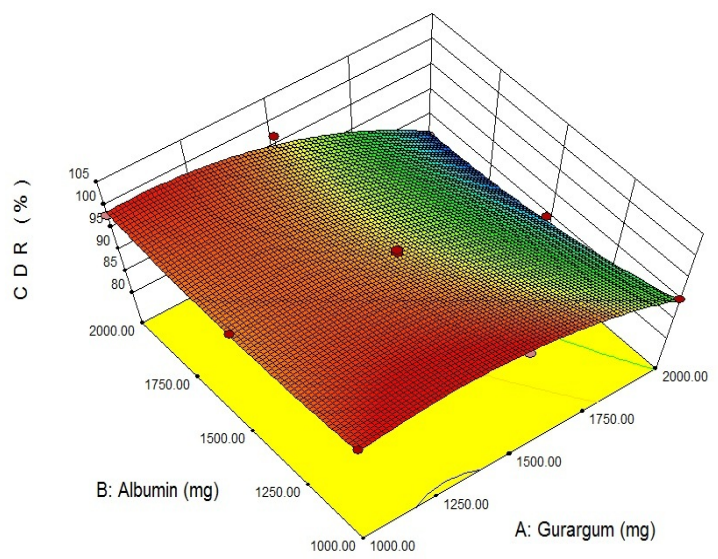

(a)

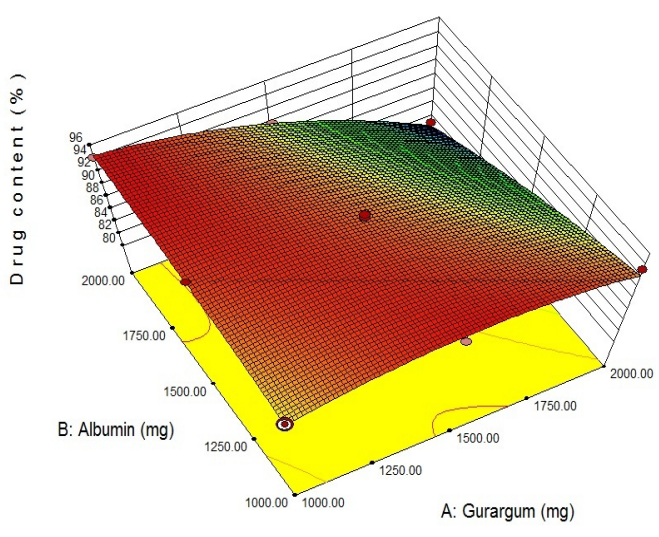

(b)

Fig. 4: 3-D surface response plots showing relative effects of Guargum and Egg albumin on (a) percent Cumulative drug release (b) drug content uniformity for formulation B1-B13 prepared by Guargum and Egg albumin.
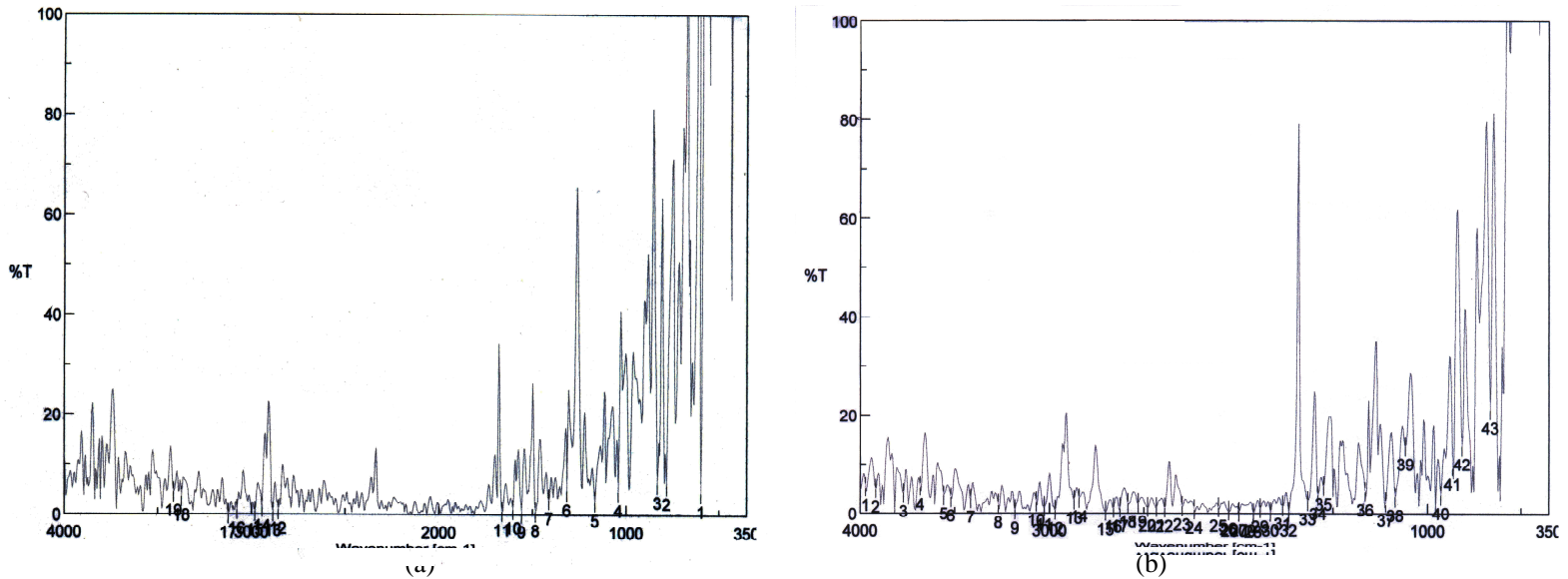

Fig. 5: IR spectrum of (a) Optimized formulation prepared by synthetic polymers B3 (Eudragit RSPO-Eudragit RLPO) (b) optimized formulation prepared by natural polymers B7 (Guargum-Albumin). 

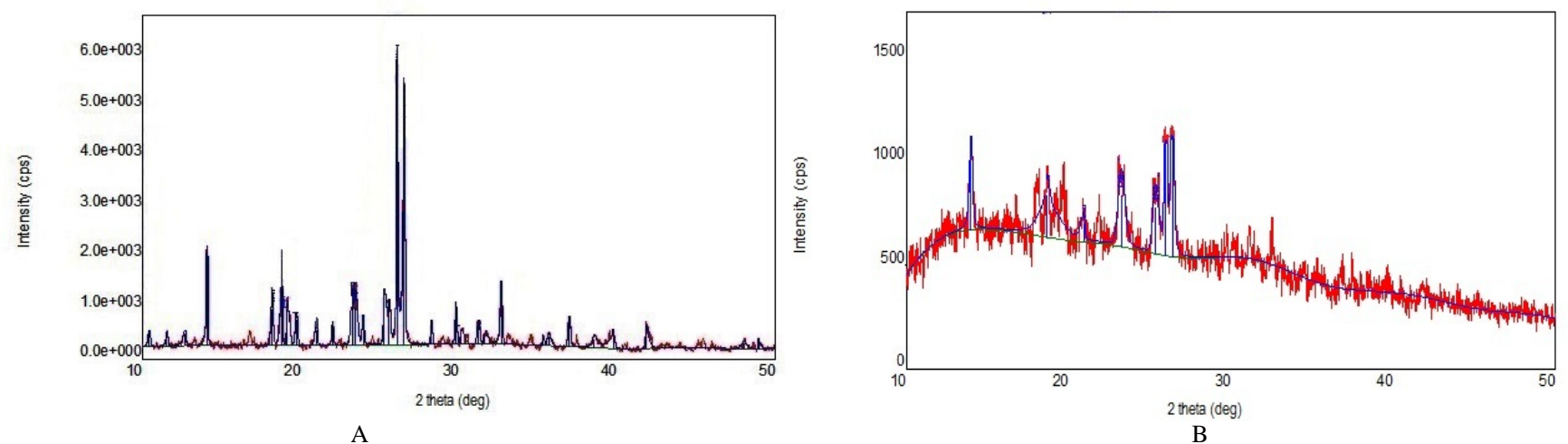

A

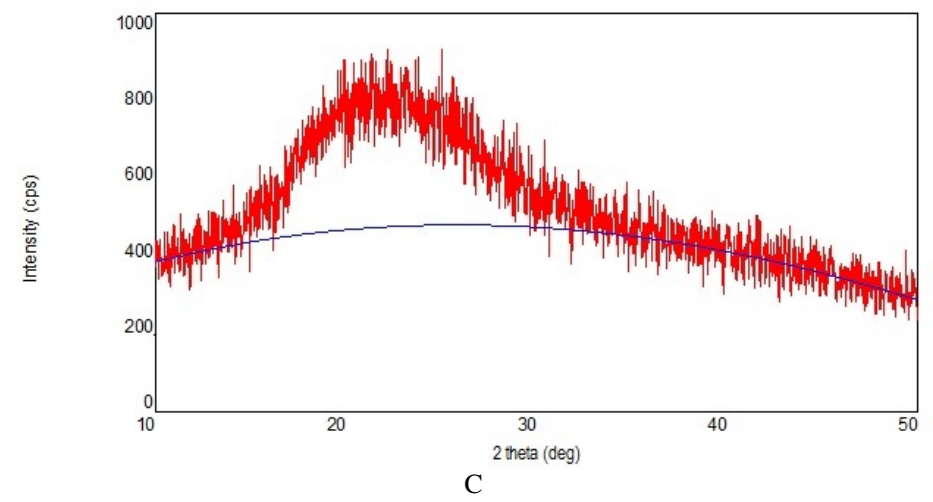

Fig. 6: XRD of (a) Metoclopramide HCL (b) Optimized formulation prepared by synthetic polymers B3 (Eudragit RSPO-Eudragit RLPO) (b) optimized formulation prepared by natural polymers B7 (Guargum-Albumin).

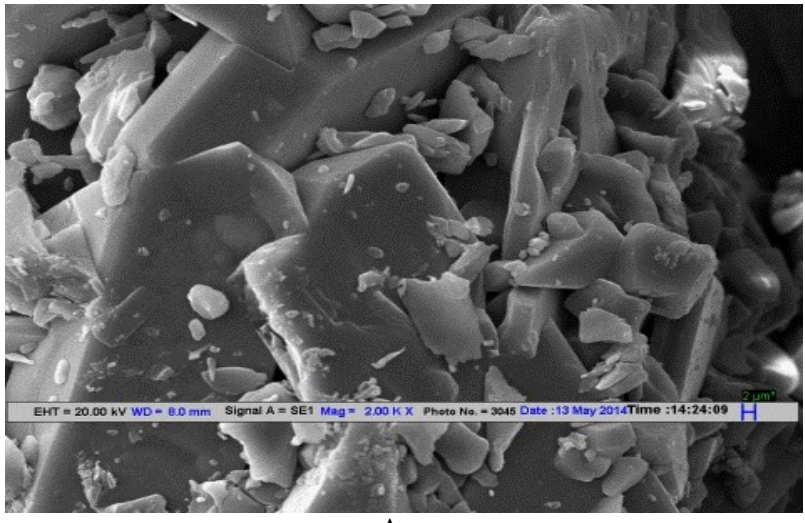

A

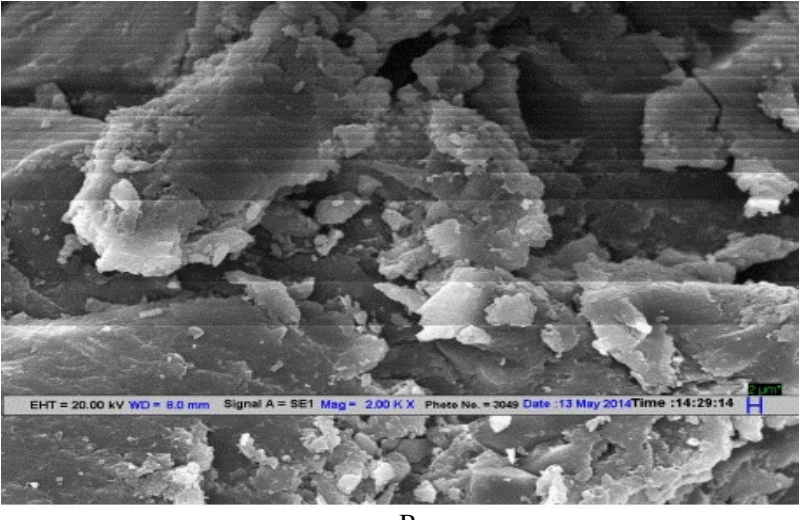

B

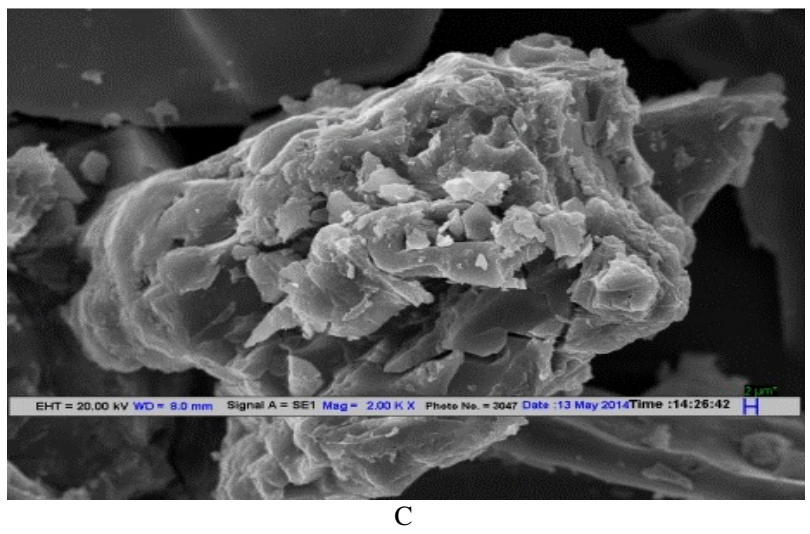

Fig. 7: SEM analysis of (a) Metoclopramide $\mathrm{HCl}$ (b) ) Optimized formulation prepared by synthetic polymers B3 (Eudragit RSPO-Eudragit RLPO) (b) optimized formulation prepared by natural polymers B7 (Guargum-Albumin). 


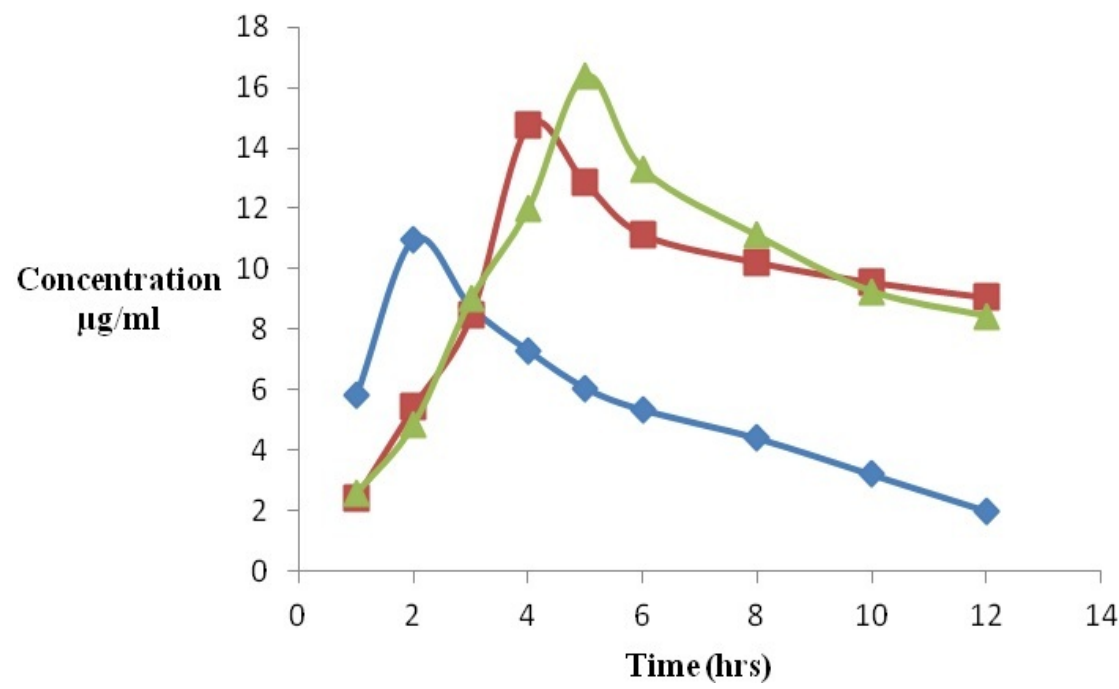

Fig. 8: Pharmacokinetic graph ploted between concentration $(\mu \mathrm{g} / \mathrm{ml}) \mathrm{v}_{\mathrm{s}}$ time $(\mathrm{hrs})$ of Drug $(\diamond)$,Optimized Formulation prepared by synthetic polymers $\mathrm{H}-$

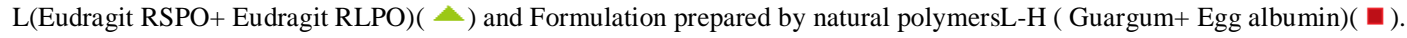

\section{CONCLUSION}

In this study, the statistical analysis of cumulative drug release and drug content uniformity shows that the solid dispersion of Metoclopramide $\mathrm{HCl}$ sustained the release rate of drug for a prolong period of time $12 \mathrm{hrs}$ and shows shows to increase the bioavailability and simultaneously decrease the dosing interval as well as dosing amount. The formulation minimizes the blood level oscillations, dose related adverse effects and cost and ultimately improve the patient compliance and drug efficiency. The in vivo study show that the the half life of soild dispersion was increased than the API of metoclopramide $\mathrm{HCl}$.As well as the study show that both formulation prepared by separately synthetic and natural polymers are produced sustained release drug profile but formulation prepared by eudragit RSPO and eudragit RLPO is more sustained than formulation prepared by Guargum and Egg Albumin.

\section{ACKNOWLEDGEMENT}

The authors are humbly thankful to I.T.S Paramedical college Muradnagar for providing lab and library facilities. I consider my privilege to express Vaikunth chemical PVT, Gujrat for providing me Metoclopramide HCL as gift sample .

\section{REFERENCE}

Anupama S, Pramod KS, Rishabha M. Release Behavior of Drugs from Various Natural Gums and Polymers. Polimery w Medycynie 2011; T.41: $\mathrm{Nr} 4$.

Aydan G, Hakan A, Fatma A. Preparation and characterization of ketoprofen loaded albumin microspheres. Turk J Biochem 2012; 37(2):120-128

Deshmukh VN, Singh SP, Sakarkar DM. Formulation and evaluation of sustained release Metoprolol Succinate tablet using hydrophilic gums as release modifiers. Int. J. Pharm. Tech. Res., 2009; 1 (2): 159-163.
Dusane AR, Gaikwad PD, Bankar V, Pawar SP. A review on: sustained release technology. International Journal of Research in Ayurveda and Pharmacy, 2011;2(6):1701-1708.

Hemalatha K, Lathaeswari R, Suganeswari M, Senthil KumarV, Anto Shering M. Formulation And Evaluation Of Metoclopramide Hydrochloride Microbeads By Ionotropic Gelation Method. International Journal of Pharmaceutical \& Biological Archives, 2011; 2(3):921-925.

Ifat $\mathrm{K}$, Aba P, Michael F. Correlation between drug release kinetics from proteineous matrices and protein folding: elasticity and compressibility study. Journal of Controlled Release, 2000; (67):261-274.

Kannan C, Karunanithi V, Janarthanan S and Dheivasigamani V. Formulation and in vitro Evaluation of Gastroretentive Rosiglitazone maleate Floating Tablets. International Journal of Chemical and Pharmaceutical Sciences, 2010; Vol.1 (1):26-32.

$\mathrm{Lu} \mathrm{B}$, Wen R, Yang H, He Y. Sustained-release tablets of indomethacin-loaded microcapsules: preparation, in vitro and in vivo characterization. Int J Pharm, 2007; 21;333(1-2):87-94.

Mazumder R, Nath LK, Haque A, Maity T, Choudhury PK, Shrestha B, Chakraborty M, Pal R N. Formulation and in vitro evaluation of natural polymers based microspheres for colonic drug delivery. Int. J. Pharm. Pharmaceut. Sci, 2010; 2 (1):211-219.

Menaka M, Pandey VP. Nasal Drug Delivery System as a Potential for Nasal Solution of Metoclopramide Hydrochloride - In Vitro and In Vivo Properties, Research Journal of Pharmaceutical, Biological and Chemical Sciences, 2013; 967-975.

Patel MP, Ashok K, Suresh VK, Someshwara RB. Design and evaluation of controlled release matrix tablets of metoclopramide hydrochloride using hydrophilic polymers . Int J Curr Pharm Res, 2012; 4(3): 64-69.

Rashmika B, VeenaV, Sandeep K, Bhikshapathi DVRN. Formulation development and In Vivo evaluation of Fexofenadine $\mathrm{HCl}$ solid dispersions by spray drying technique. Scholars Research Library Der Pharmacia Lettre, 2013; 5 (6):73-82.

Rosario P, Daniela S, Maria Angela V, Flavio F, Giovanni P. Characterization of the Mechanism of Interaction in Ibuprofen-Eudragit RL1001 Coevaporates. Drug Development and Industrial Pharmacy, 2004; 30(3): 277-288.

Sandip C, Sanjay A, Dilip D. Design and evaluation of once daily sustained release matrix tablets of Nicorandil. International Journal of Pharmacy and Pharmaceutical Sciences, 2011;3( 2):13-18.

Sharif Md. S, Mamumur R, Md. Anwar ul I, Reza ul J. Heating and chemical denaturation of egg Albumin Matrix and its effect on the Release Kinetic of Theophylline from tablets.Pakistan Journal of Biological Science, 2004; 7(9): 1488-1492. 
Sushilkumar SP, Shirish UN, Dinesh KS. Designing of Ritonavir Solid Dispersion through Spray Drying, Scholars Research Library Der Pharmacia Lettre, 2011; 3 (5): 213-223.

Shuxin W, Yingqian S, Xiuxiang Q, Fengping T. Improved Bioavailability of Poorly Water-Soluble Drug Curcumin in Cellulose Acetate Solid Dispersion. AAPS PharmSciTech, 2012; 13(1): 159-166.

Tyagi R, Dhillon V. Enhancement OF Solubility and Dissoultion rate of Domperidone using Cogrinding and Kneading Technique. Journal of Drug Delivery \& Therapeutics, 2011; 2(4): 152-158.

Vinay P, Roopa SP, Kusum D, Sarasija S. In vitro-in vivo evaluation of fast-dissolving tablets containing solid dispersion of pioglitazone hydrochloride. J Adv Pharm Technol Res, 2012; 3(3): 160 170.

Vinay W, Manjunath S Y, M. Mohan V. Development and validation of uv spectroscopic method for determination of metoclopramide hydrochloride in bulk and tablet formulation. International Journal of Pharmacy and Pharmaceutical Sciences, 2011; Vol 3, Issue 3: 171-174.

Viral S, Shailendra S P, Rakesh K J, Abhishek J, R.V. Sheorey. Formulation and evalution of mouth dissolving tablets of metoclopramide hydrochloride by direct compression technique. International journal of drug discovery and herbal research , 2011; 1(2):100-103.
Welling PG, Tse FLS. Marcel Dekker Inc.; New York and Basel: 1988. Pharmacokinetics: Regulatory, Industrial, Academic, Perspectives. pp. 308.

Wu C, Liao Q, Yao M, Xu X, Zhou Y, Hou X. Effect of natural borneol on the pharmacokinetics and distribution of nimodipinein mice, Eur J Drug Metab Pharmacokinet 2013. Available from: 10.1007/s13318013-0135-z.

Yadav AS, Kumar PA, Vinod R, Rao BS, Kulkarni SV. Design and evaluation of guar gum based controlled release matrix tablets of Zidovudine. J. Pharmaceut. Sci. Technol 2010; 2 (3): 156-162.

Zheng C, Xiaolu L, Zhufen L, Jie Z, Feizhen W, Zhaoxiang Y, Junxue $\mathrm{P}$, Zhongqiu L. Preparation and evaluation of sustained-release solid dispersions co-loading gastrodin borneol as an oral brain-targeting enhancer, Acta Pharmaceutica Sinica B 2014;4(1): 86-93.

\section{How to cite this article:}

Neha SL, Neelam Singh L. Sustained release solid dispersion of Metoclopramide HCL: formulation, evaluation and pharmacokinetic studies. J App Pharm Sci, 2015; 5 (03): 055-065. 